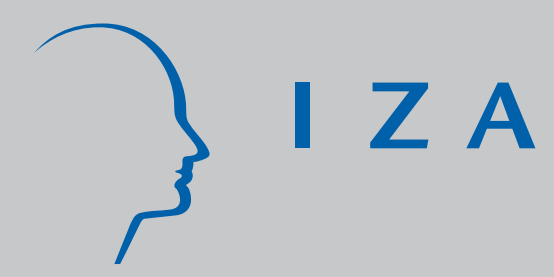

IZA DP No. 3167

Ethnic Competition and Specialization

Martin Kahanec

November 2007 


\title{
Ethnic Competition and Specialization
}

\author{
Martin Kahanec \\ IZA \\ Discussion Paper No. 3167 \\ November 2007 \\ IZA \\ P.O. Box 7240 \\ 53072 Bonn \\ Germany \\ Phone: +49-228-3894-0 \\ Fax: +49-228-3894-180 \\ E-mail: iza@iza.org
}

Any opinions expressed here are those of the author(s) and not those of the institute. Research disseminated by IZA may include views on policy, but the institute itself takes no institutional policy positions.

The Institute for the Study of Labor (IZA) in Bonn is a local and virtual international research center and a place of communication between science, politics and business. IZA is an independent nonprofit company supported by Deutsche Post World Net. The center is associated with the University of Bonn and offers a stimulating research environment through its research networks, research support, and visitors and doctoral programs. IZA engages in (i) original and internationally competitive research in all fields of labor economics, (ii) development of policy concepts, and (iii) dissemination of research results and concepts to the interested public.

IZA Discussion Papers often represent preliminary work and are circulated to encourage discussion. Citation of such a paper should account for its provisional character. A revised version may be available directly from the author. 
IZA Discussion Paper No. 3167

November 2007

\section{ABSTRACT}

\section{Ethnic Competition and Specialization ${ }^{*}$}

Are ethnic specialization and thus a downward sloping labor demand curve fundamental features of labor market competition between ethnic groups? In a general equilibrium model, this paper argues that spillover effects in skill acquisition and social distances between ethnic groups engender equilibrium regimes of skill acquisition that differ in their implications for ethnic specialization. Specifically, fundamental relationships through which relative group sizes determine whether ethnic specialization arises and in what degree are established. Thus, this paper theoretically justifies a downward sloping labor demand curve and explains why some ethnic groups earn more than others, ethnic minorities underperforming or outperforming majorities.

JEL Classification: J15, J24, J70, O15

Keywords: human capital, ethnic group, labor market, ethnic specialization, spillover effects

Corresponding author:

Martin Kahanec

IZA

P.O. Box 7240

53072 Bonn

Germany

E-mail: kahanec@iza.org

\footnotetext{
"I am grateful to Barry R. Chiswick, Carmel U. Chiswick, Sjak Smulders, William J. Baumol, Patrick Francois and audiences at various seminars at IZA Bonn, Tilburg University and NAKE for their helpful comments on previous drafts of this paper. All remaining errors are mine. Financial support from Volkswagen Foundation for the IZA project on "The Economics and Persistence of Migrant Ethnicity" is gratefully acknowledged.
} 


\section{Introduction}

We live in a world where social and economic interaction of different ethnic groups groups of people that differ in terms of shared cultural heritage, race, religion, language, history, beliefs, customs, values, or morals - is rather the rule than an exception. African-Americans in the US, Turks in Germany, and Roma in Central and Eastern Europe are all examples of distinct ethnic groups in larger societies. Social and economic interaction between ethnic groups exhibits several phenomena that intrigue social scientists and economists in particular. The scale puzzle that (i) minority ethnic groups on average earn less than the majority population and that (ii) this earnings differential is increasing in minority share in population in a given region is a well established empirical regularity. ${ }^{1}$ Another widely documented phenomenon is the occupational segregation of ethnic groups. Altonji and Blank (1998) report that minority workers are overrepresented in less skilled jobs and Blacks in the US are overrepresented in specific kinds of jobs such as public administration. Further empirical accounts of occupational segregation include Blalock (1957), Brown and Fuguitt (1972), and Hirschman and Wong (1984). Grant and Hamermesh (1981), Grossman (1982), Borjas (1983, 1987, 2003), and Kahanec (2006a) provide some evidence for imperfect substitutability of ethnic labor and downward sloping demand for ethnic labor. Richman (2006) discusses how community institutions and occupational specialization create economic advantage for Jewish communities.

There remain gaps in our understanding of the underlying nature of labor market competition between different ethnic groups, however. Are there fundamental mechanisms that drive ethnic groups to specialize in certain skills and jobs such that their labor is imperfectly

\footnotetext{
${ }^{1}$ See for example Blalock (1956, 1957), Heer (1959), Brown and Fuguitt (1972), Frisbie and Neidert (1977) and Tienda and Lee (1987).
} 
substitutable in the labor market and thus the demand for ethnic labor is downward sloping? What conditions determine whether being a member of ethnic minority is an economic advantage or disadvantage? Since the groundbreaking work of Becker (1957), different forms of discrimination have been suggested to explain significant differentials in labor market performance between ethnic groups. ${ }^{2}$ This literature offers some answers to the abovementioned questions, viewing ethnic specialization as a result of discrimination constraints imposed on the behavior of some ethnic groups. For example, discrimination may have driven ethnic groups into certain less attractive sectors of the economy. From a different viewpoint, ethnic specialization could be explained as a consequence of different "tastes" of different ethnic groups for certain skills, jobs, or occupations. ${ }^{3}$

In this paper, I explain labor market specialization of people of different ethnicities and the resulting earnings differentials as driven by their choice between heterogeneous skills and social networks - social structures between individual actors that facilitate their social interaction such as schools or families - where these skills are acquired. In particular, I argue that ethnic specialization is a persistent feature of the labor market even in a world free of discrimination. While the defining cultural and social differences between ethnic groups are instrumental in generating different incentives in skill acquisition for different ethnic groups in the transaction costs tradition, they are not assumed to imply any ad hoc taste differentials over different skills. The argument draws on two fundamental properties of social interaction between different ethnic groups in human capital acquisition: spillover effects in social networks where skills are acquired and social distance between ethnic groups.

\footnotetext{
${ }^{2}$ The discrimination literature is immense. Major contributions include Welch (1967), Arrow (1972a, 1972b, 1973), who discuss the so-called taste for discrimination theories; Phelps (1972), Arrow (1972a, 1972b, 1973), Aigner and Cain (1977), Coate and Loury (1993), and Lundberg and Startz (2002) elaborate on the concept of statistical discrimination. Altonji and Blank (1999) summarize this literature extensively.

${ }^{3}$ See e.g. Hofstede (1980).
} 
That individuals learn from their peers, friends, and neighbors has been proposed by a number of scholars. As Lucas (1988) points out, "human capital accumulation is a social activity, involving groups of people in a way that has no counterpart in the accumulation of physical capital.” A number of scholars, such as Glaeser et al. (2002), Foster and Rosenzweig (1995), and Lazear (1999), maintain that social interaction in social networks involves positive externalities such that the aggregate resources of a network exceed the naïve sum of individual contributions. Foster and Rosenzweig (1995) develop a framework in which the efficiency of social learning improves in the number of involved individuals. ${ }^{4}$ Based on this literature, I adopt the premise that skill acquisition exhibits spillover effects such that the benefits (in terms of the efficiency of skill acquisition) from social interaction in a given social network increase in the number of members of that network. ${ }^{5}$

Naturally, benefits from social interaction depend not only on the number of individuals one interacts with but also on who those individuals are. In the context of inter-ethnic social interaction, sociocultural differences between ethnic groups determine the efficiency of social interaction in any social network. In line with Poole (1927) and Lazear (1999), I define social distance to be the measure of subjective and objective dissimilarities between ethnic groups that hinders social interaction between the members of these groups. A natural corollary of this definition and the second essential assumption of the paper is that an individual's ability to

\footnotetext{
${ }^{4}$ Allen (1982), Ellison and Fudenberg (1993, 1995), and Bala and Goyal (1998) investigate the role of social interaction in learning about optimal actions. Valente (1995), Feick and Price (1987), Gladwell (2000), and Foster and Rosenzweig (1995) substantiate such approach and observe that social networks are an important vehicle of information sharing. These authors document that colleagues, friends, or neighbors share information about their discoveries, experiment outcomes, or search results. Conley and Udry (2005), Foster and Rosenzweig (1995), and Munshi (2004) provide evidence that social interactions significantly affect farmers' profitability upon adoption of new technologies, arguing that this finding implies that farmers learn about the best practices in social interaction with their peers and neighbors, rather than only mimicking their behavior. Goyal (2003) surveys the literature on social learning.

${ }^{5}$ Such effects are also known as network externalities.
} 
benefit from social interaction in a given social network negatively depends on her social distance to the other members of this network. ${ }^{6}$

To study specialization of ethnic groups, I explore the character of social networks where skills are acquired. ${ }^{7}$ Some social networks, including families, kinships, and certain religious groups, expatriate communities, schools and clubs permit memberships exclusively from a single ethnic group. In contrast, most schools, student societies, workplaces, academic communities, and cybernetworks such as the Internet are inclusive, permitting membership from any ethnic group. ${ }^{8}$ These exclusive and inclusive social networks are typically different with respect to their complexity, objectives, functions, and, as a consequence, the type of skills they support. On the one hand, in exclusive social networks people typically acquire less formal and non-cognitive skills such as verbal and non-verbal communication skills, general social knowledge and socialization skills, and capability of self-motivation, but also particular arts and crafts skills specific to exclusive social networks. ${ }^{9}$ On the other hand, inclusive social networks generally facilitate acquisition of more formal and cognitive skills such as those in e.g. mathematics, medicine, metal processing, machine operating, and banking. ${ }^{10}$ The key insight of this paper is that in a world where heterogeneous skills are available in skill-specific social networks the efficiency differentials engendered by spillover effects, social distances, and different sizes of ethnic groups systematically expose individuals of different ethnicities to different incentives as

\footnotetext{
${ }^{6}$ Note that social distance as defined here is fully symmetric at the individual level and essentially engenders transaction costs in social interaction between members of different ethnic groups. In contrast to Akerlof (1997), who studies endogenous social distance between homogeneous agents, I consider social distance between members of different ethnic groups to be a predetermined variable that reflects the defining distinctiveness of ethnic groups.

${ }^{7}$ Note the different role of social networks in this paper from that discussed by Buhai and van der Leij (2006), who study occupational segregation between social groups as resulting from the inbreeding bias in job referral social networks.

${ }^{8}$ Thus, exclusive social networks are always segregated. Inclusive social networks may be integrated as well as segregated; the distinction made in this paper is that exclusiveness (inclusiveness) is understood as exogenous institutional constraint on network membership while segregation (integration) as endogenous variable concerning equilibrium organization of social interaction as discussed below.

${ }^{9}$ For example child care, cooking, and maintenance skills acquired in the family.

${ }^{10}$ Cognitive and non-cognitive skills are discussed in e.g. Coleman et al. (1966) and Heckman (2000).
} 
concerns skill choice. In effect, under certain condition that are shown to depend on relative group sizes, these differing incentives make ethnic groups acquire different (combinations of) skills. The conditionality of the result on ethnic specialization has important consequences for relative performance of ethnic groups in the labor market and helps us understand some of the abovementioned empirical findings.

Given these premises, I develop the argument as follows. First, the elementary properties of ethnic competition in the labor market are described in a stylized model. Assuming imperfect substitutability of ethnic labor, I explain the substitution effect, whereby under imperfect substitutability of ethnic labor an efficiency unit of labor of relatively larger ethnic groups sells at relatively lower wage. Furthermore, I establish that spillovers in skill acquisition and interethnic social distances disadvantage smaller ethnic group in terms of efficiency of human capital acquisition. Next, I develop an argument that these two properties of social interaction between ethnic groups engender specific equilibrium regimes of skill acquisition, some of which exhibit imperfect substitutability of labor of different ethnic groups. Finally, I discuss the results and conclude.

\section{The Model}

\subsection{Demand}

To establish the substitution effect, consider an economy populated by the continua of individuals from two ethnic groups, $I$ and $J$, with measures $I$ and $J$ and elements $i$ and $j$, respectively. Assuming $I+J=1$ and $I \leq J$ without loss of generality, one can refer to ethnic group $I$ as the minority and $J$ as the majority. Social distance between minority and majority individuals marks the distinction between the two ethnic groups. Individual membership in one 
of the two ethnic groups is predetermined for each individual. Except for group membership and social distance, all individuals are identical with respect to their preferences and endowments. Individual preferences are represented by a standard utility function $u(\cdot)$ defined on individual consumptions of the consumption good, $C_{k}$, where $k \in\{i, j\}$.

Let the consumption good be produced by combining labor of minority and majority individuals, $H_{i}$ and $H_{j}$, respectively, according to the aggregate production function:

$$
C=F\left(H_{I}, H_{J}\right)
$$

where $H_{I} \equiv \int_{0}^{I} H_{i} d i$ and $H_{J} \equiv \int_{0}^{J} H_{j} d j$. This production function is assumed to exhibit standard properties: positive marginal product of each input, concavity, and constant returns to scale (CRS). Assuming that production takes place in a perfectly competitive industry, wages equal marginal productivities, $W_{i}=F_{H_{I}}$ and $W_{j}=F_{H_{J}}$.

The following proposition states that whenever the production technology (1) is symmetric with respect to minority and majority labor inputs, which is a natural baseline assumption, the ethnic group that supplies more labor earns a lower wage per unit of efficient labor and vice versa. This is a version of the elementary economic law of diminishing marginal product that implies that scarcer resources sell at higher prices, ceteris paribus.

Proposition 1: In a perfectly competitive industry, whenever the production technology (1) is symmetric such that $F\left(H_{I}, H_{J}\right)=F\left(H_{J}, H_{I}\right)$ for every $H_{I}$ and $H_{J}$ and satisfies the properties $F_{H_{I}}>0, F_{H_{J}}>0, F_{H_{I}, H_{I}}<0$, and $F_{H_{J}, H_{J}}<0, H_{I} \leq H_{J}$ implies $W_{I} \frac{\geq}{<} W_{J}$.

Proof: That $F\left(H_{I}, H_{J}\right)=F\left(H_{J}, H_{I}\right)$ for every $H_{I}$ and $H_{J}$ implies $F_{H_{I}}=F_{H_{J}}$, whenever 
$H_{I}=H_{J}$. If $H_{I} \frac{<}{>} H_{J}, F_{H_{I}, H_{I}}<0$ and $F_{H_{J}, H_{J}}<0$ imply that $F_{H_{I}} \frac{\geq}{<} F_{H_{J}}$ and thus, given perfect competition, $W_{I} \stackrel{>}{<} W_{J}$.

Consider now the case when efficient labor of different ethnic groups is imperfectly substitutable in the labor market. In particular, let an increase in the supply of minority (majority) labor decrease minority (majority) wage relatively more than majority (minority) wage. In other words, let the cross partial elasticity of complementarity be smaller than own partial elasticity of complementarity. ${ }^{11}$ Formally,

$$
\frac{F F_{H_{I}, H_{I}}}{F_{H_{I}} F_{H_{I}}}<\frac{F F_{H_{J}, H_{I}}}{F_{H_{J}} F_{H_{I}}}
$$

and

$$
\frac{F F_{H_{J}, H_{J}}}{F_{H_{J}} F_{H_{J}}}<\frac{F F_{H_{I}, H_{J}}}{F_{H_{I}} F_{H_{J}}} .
$$

For the sake of exposition, I denote $w \equiv W_{I} / W_{J}$ and $h \equiv H_{i} / H_{j}$ and adopt the representative agent hypothesis group-wise, such that $H_{I}=H_{i} I$ and $H_{J}=H_{j} J$. It follows that $H_{I} / H_{J}=h(I /(1-I))$ and thus relative wages are a function of relative labor supplies and group sizes, $w \equiv w(h, I)$. In addition, let us for the moment assume that $H_{i}$ and $H_{j}$, and thus $h$ as well, are independent of $I$. Proposition 2 states the result that relative wages decrease in both the relative minority size $I$ and minority-majority ratio of per capita supply of efficient labor $h$.

\footnotetext{
${ }^{11}$ The Hicks elasticity of complementarity measures the effect on the relative price of a given factor of production of a change in the relative quantity of that factor, holding marginal costs and the quantities of other factors constant. See Hicks (1970).
} 
Proposition 2 (The substitution effect): Whenever the production technology (1) satisfies conditions (2) and (3), $h$ and $I$ are independent of each other, and production is perfectly competitive, $\partial w(h, I) / \partial h<0$ and $\partial w(h, I) / \partial I<0$.

Proof: Conditions (2) and (3) imply that $\frac{\partial\left(F_{H_{I}} / F_{H_{J}}\right)}{\partial H_{I}}=\frac{F_{H_{I}, H_{I}} F_{H_{J}}-F_{H_{I}} F_{H_{J}, H_{I}}}{\left(F_{H_{J}}\right)^{2}}<0$ and $\frac{\partial\left(F_{H_{I}} / F_{H_{J}}\right)}{\partial H_{J}}=\frac{F_{H_{I}, H_{J}} F_{H_{J}}-F_{H_{I}} F_{H_{J}, H_{J}}}{\left(F_{H_{J}}\right)^{2}}>0$. Given that $W_{i}=F_{H_{I}}$ and $W_{j}=F_{H_{J}}$ under perfect competition and that $F\left(H_{I}, H_{J}\right)$ is CRS, it follows that $\partial\left(W_{I} / W_{J}\right) / \partial\left(H_{I} / H_{J}\right)<0$. By definition, $\partial\left(H_{I} / H_{J}\right) / \partial h>0$ and $\partial\left(H_{I} / H_{J}\right) / \partial I>0$. The independence of $h$ and $I$ then implies $\partial w(h, I) / \partial h<0$ and $\partial w(h, I) / \partial I<0$.

Intuitively, whenever efficient labor of different ethnic groups is imperfectly substitutable such that an increase in the supply of a production factor depresses its own price more than the price of other production factors, an increase in the relative supply of a production factor depresses its relative price. Proposition 2 brings to light the substitution effect. Through this effect, ceteris paribus, relatively larger ethnic groups are hurt by the relative abundance of their labor in the labor market, as it depresses the relative wage per unit of their efficient labor. Figure 1 depicts the substitution effect. Recalling the result of Proposition 1 and assuming symmetry such that $h=1$ whenever $I=J, w(h, I)$ is decreasing in $I$ and attains the value of 1 at $I=J$. 
Figure 1. The substitution effect.

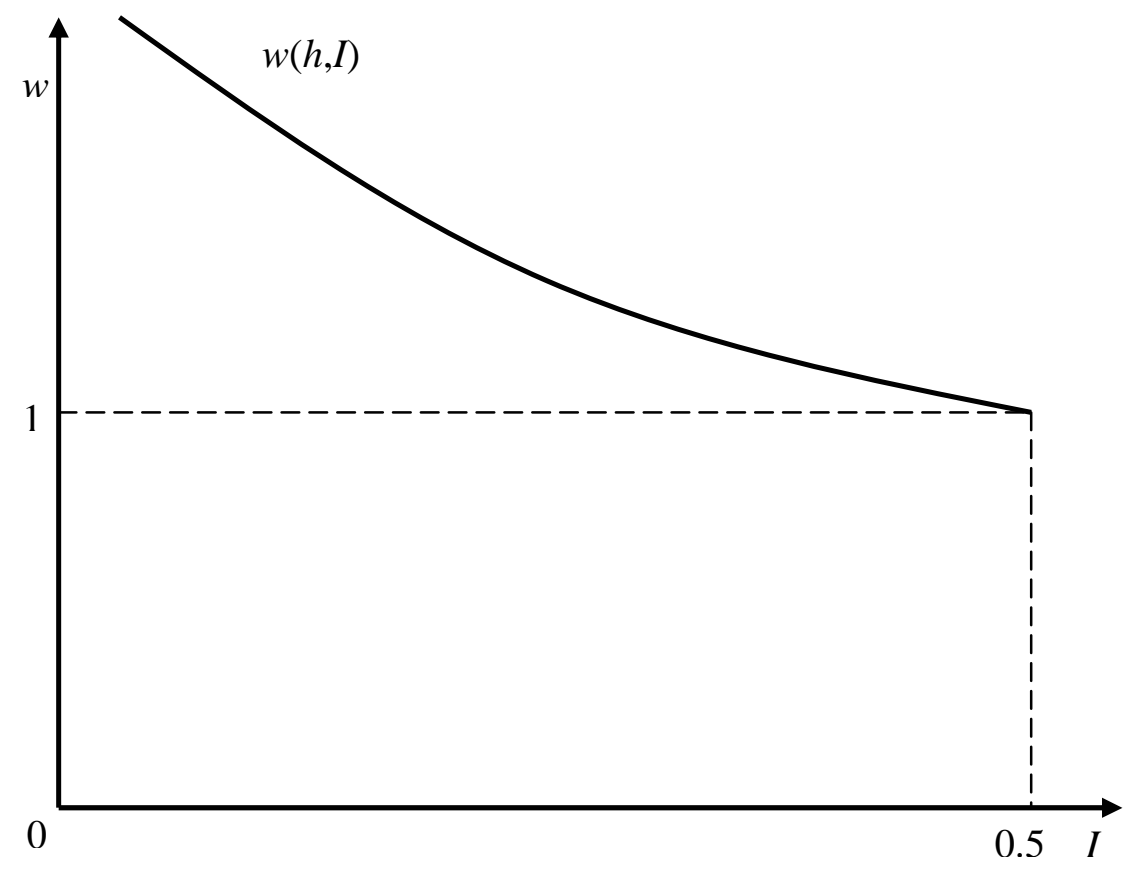

On the other hand, under the condition that labor of different ethnic groups is perfectly substitutable such that the conditions (2) and (3) hold as equalities, from the proof of Proposition 2 it is clear that $\partial w(h, I) / \partial h=0$ and $\partial w(h, I) / \partial I=0$, that is, the substitution effect is not operative.

\subsection{Supply}

In this section I characterize the supply side of the model, establishing the relationship between the share of minority (majority) individuals in the labor market and their supply of labor. For simplicity, let us assume that each individual is endowed with two units of time, one of which is inelastically supplied in the labor market and the other one is spent in skill 
acquisition. Thus, each individual faces the time constraints $L_{k}=1=Z_{k}$, where $L_{k}$ is the time individual $k$ spends in skill acquisition, spending the rest of her time, $Z_{k}$, working.

To capture the role of local spillover effects and social distance in human capital acquisition in an easily tractable way, assume for the moment that any given individual interacts with all other individuals ( $I$ minority and $J$ majority individuals) in a single economy-wide social network. Let the continuous and differentiable function $N($.$) characterize the spillover$ benefits from social interaction in this network. Throughout the paper I assume that agents take these spillover effects as given, provided the infinitesimal measure of any individual. I formalize skill acquisition technology as follows

$$
\begin{aligned}
& S_{i}=S\left(L_{i}\right)(1+N(I)+N(J /(1+\delta))) \\
& S_{j}=S\left(L_{j}\right)(1+N(I /(1+\delta))+N(J)),
\end{aligned}
$$

where $S_{i}$ and $S_{j}$ denote human capital of minority and majority workers, respectively, and the continuous and differentiable function $S\left(L_{k}\right)$ satisfies $d S\left(L_{k}\right) / d L_{k}>0$ and $d^{2} S\left(L_{k}\right) / d L_{k}^{2} \leq 0$. Given the assumptions above, $N($.$) is monotonously increasing in the numbers of individuals$ involved in social interaction, $I$ and $J .^{12}$ The parameter $\delta>0$ captures the premise that the spillover benefits from social interaction with individuals of different ethnicity decrease in social distance between ethnic groups. Social distance between members of the same ethnic group is normalized to zero. Assuming that efficient labor is the product of labor time and human capital, individual supplies of efficient labor $H_{i}$ and $H_{j}$ are

$$
\begin{aligned}
& H_{i}=\left(2-L_{i}\right) S_{i}=1+N(I)+N(J /(1+\delta)) \\
& H_{j}=\left(2-L_{j}\right) S_{j}=1+N(I /(1+\delta))+N(J),
\end{aligned}
$$

\footnotetext{
${ }^{12}$ Decreasing returns to social interaction would be a natural assumption, but it is not necessary.
} 
where the normalization $S(1)=1$ and the abovementioned assumption $L_{k}=1$ are used. ${ }^{13}$ The following proposition states that the spillover effects in human capital acquisition and the social distance between minority and majority individuals disadvantage smaller ethnic groups in terms of efficiency of human capital acquisition, if the spillover function $N($.$) satisfies the condition$ $d N(K) / d K>d N(K /(1+\delta)) / d K$ for any $K \in\{I, J\}$ and $\delta>0$. This condition, adopted henceforth, implies that the marginal benefits from social interaction are not decreasing too fast. It is satisfied, for example, by any homogeneous function of degree $d>0$.

Proposition 3 (The efficiency effect): Given a positive social distance $\delta$ and that $N($.$) satisfies$ $d N(K) / d K>d N(K /(1+\delta)) / d K$ for any $K \in\{I, J\}$, technologies (6) and (7) imply that $\partial h(I) / \partial I>0$ and, because $I<J, H_{i}<H_{j}$.

Proof: $\quad d H_{i} / d I=\frac{d N(I)}{d I}+\frac{d N(J /(1+\delta))}{d J} \frac{d J}{d I}$ and $d H_{j} / d I=\frac{d N(I /(1+\delta))}{d I}+\frac{d N(J)}{d J} \frac{d J}{d I}$. Since $d N(K) / d K>d N(K /(1+\delta)) / d K, \frac{d N(I)}{d I}>\frac{d N(I /(1+\delta))}{d I}$ and $\frac{d N(J)}{d J}>\frac{d N(J /(1+\delta))}{d J}$, for any admissible $I, J$, and $\delta$. Because $J=1-I, d J / d I=-1$. Therefore, $d H_{i} / d I>d H_{j} / d I$ for any $I$. Noting that if $I=J$ it holds that $H_{i}=H_{j}, d H_{i} / d I>d H_{j} / d I$ for any $I$ implies $H_{i}<H_{j}$ for any $I<J$. It follows that $d h / d I=\frac{d H_{i} / d I H_{j}-H_{i} d H_{j} / d I}{H_{j}^{2}}>0$.

Proposition 3 exemplifies the second of the two key relationships discussed in this paper - the efficiency effect. Through this effect larger ethnic groups are relatively more

\footnotetext{
${ }^{13}$ Without any bearing on the argument, these technologies of producing efficient labor can be reinterpreted as the production functions of intermediate goods $H_{k}$, which are inputs in the production of the consumption good $C$.
} 
efficient than smaller ones in human capital acquisition. Intuitively, a member of a smaller ethnic group has a relatively smaller pool of members of her own ethnic group with whom she can socially interact without being obstructed by social distance. In effect, the chance that she is disadvantaged in social interaction by the inefficiencies engendered by social distance is relatively higher than that of a member of a relatively larger ethnic group. Figure 2 depicts $h$ as a function of $I$, which is upward sloping due to the efficiency effect and reaches unity at $I=J$.

Figure 2. The efficiency effect.

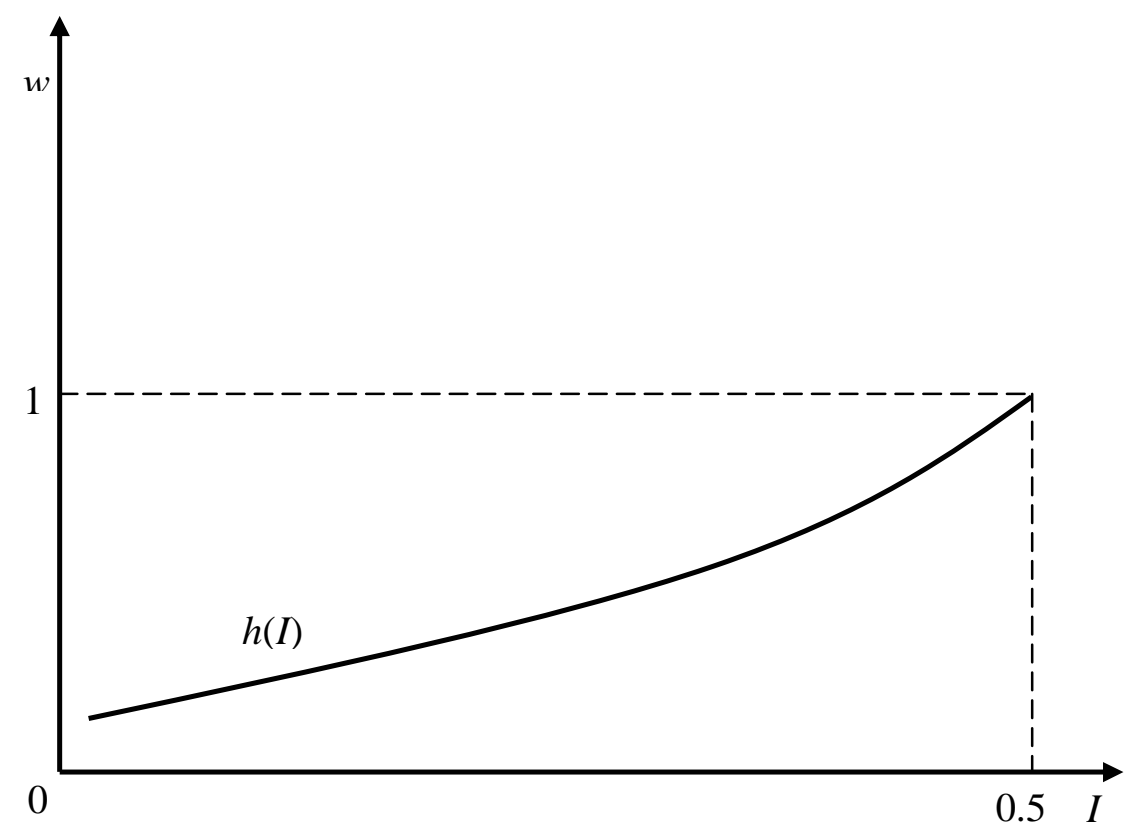

\subsection{The Equilibrium}

Sections 2.1 and 2.2 above depict the properties of the relationship between minoritymajority wage and labor ratios, $w$ and $h$, and minority percentage, $I$, as determined by the demand and supply sides, respectively. In this section I turn to the equilibrium properties of these relationships. Since $h$ is independent of $w$, as apparent from Section 2.2, the equilibrium 
properties of $h$ as a function of $I$ are fully determined by the supply side and thus not different from those presented in Proposition 3. Therefore, in the equilibrium, $h(I)$ is increasing in $I$.

As concerns the properties of the relationship between the minority-majority wage ratio and minority percentage in the equilibrium, these are determined by the demand side, as depicted in Proposition 2, but also by the supply side, whereby $h$ is a function of $I$. We know from the demand side analysis of Section 2.1 that, taking $h$ and $I$ independent of each other, $w(h, I)$ is decreasing in each of its arguments. Section 2.2 tells us that $h$ is an increasing function of $I$, however. Proposition 4 resolves the equilibrium relationship between $w$ and $I$, establishing that Proposition 2 and Proposition 3 imply that minority-majority wage ratio is decreasing in minority percentage in the equilibrium, as depicted in Figure 1.

Proposition 4: Whenever the production technology (1) satisfies conditions (2) and (3), $\delta>0$, and $N($.$) satisfies d N(K) / d K>d N(K /(1+\delta)) / d K$ for any $K \in\{I, J\}, \partial w(I) / \partial I<0$.

Proof: From Proposition 2, given the independence of $h$ and $I$, conditions (2) and (3) imply that $\partial w(h, I) / \partial h<0$ and $\partial w(h, I) / \partial I<0$. From Proposition 3, given $\delta>0$ and that $N($.$) satisfies$ $d N(K) / d K>d N(K /(1+\delta)) / d K$ for any $K \in\{I, J\}, \partial h(I) / \partial I>0$. It is straightforward to see that $\partial w(h, I) / \partial h<0, \quad \partial w(h, I) / \partial I<0, \quad$ and $\quad \partial h(I) / \partial I>0$ imply that $w(h(I), I)=w(I)$ is decreasing in $I$.

This result is intuitive. Due to the substitution effect, minority-majority relative wage decreases in minority share. An increase in the share of minority people increases their efficiency in human capital acquisition through the efficiency effect such that their per capita supply of 
efficient labor increases relative to the per capita supply of efficient labor of majority people. This increase further depresses minority-majority relative wage through the substitution effect.

\section{Specialization of ethnic groups}

The substitution and the efficiency effects link the nature of ethnic competition in the labor market to the relative sizes of ethnic groups. In particular, the relative strengths of these effects determine the properties of $w(I), h(I)$, and relative earnings $\omega(I) \equiv w(I) h(I)$ as functions of the relative sizes of ethnic groups. ${ }^{14}$ While these two effects can, in principle, generate various patterns of ethnic earnings inequality, there is an important precondition for the substitution effect to be operative, namely, specialization of ethnic groups such that the conditions (2) and (3) are satisfied. Otherwise, ethnic earnings inequality is driven solely by the efficiency effect, whereby relatively larger ethnic groups outperform smaller ones. This is easily seen in the model, since perfect substitutability of minority and majority labors implies that $F_{H_{I}}=F_{H_{J}}$ and thus $W_{I}=W_{J}$, which in turn implies that $\omega(I)=h(I)$. Proposition 3 then implies that $\omega(I)<1$ and $\partial \omega(I) / \partial I>0$.

The fundamental insight of this section is that local spillover effects and minoritymajority social distance under some conditions drive members of different ethnic groups to choose different combinations of exclusive and inclusive skills to acquire. Such ethnic specialization engenders the substitution effect and causes the demand for labor of any given ethnic group to be decreasing in this group’s relative size.

\footnotetext{
${ }^{14}$ Kahanec (2006b) discusses the conditions under which these effects explain the scale puzzle.
} 
To see this, let us relax the assumption about the inelastic allocation of time, such that individual is now free to chose how much of the endowed time he spends working and how much acquiring human capital. In addition, introducing the heterogeneity of skills in the model, I let the individual choose between exclusive and inclusive skills. Re-normalizing the time constraint such that each individual has one unit of time we obtain:

$$
L_{k x}+L_{k n}+Z_{k x}+Z_{k n} \leq 1
$$

where $Z_{k m}$ is the time spent by individual $k$ in utilizing skill $m \in\{x, n\}$ of, respectively, exclusive or inclusive type, in production.

Given that there are skill specific social networks where skills are acquired, technologies (4) to (7) need to be reformulated. In particular, denoting social networks correspondingly to the skills they entail, we assume that the following functions describe acquisition of skills

$$
\begin{aligned}
& S_{i m}=S\left(L_{i m}\right)\left(1+N\left(I_{i m}\right)+N\left(J_{i m} /(1+\delta)\right)\right) \\
& S_{j m}=S\left(L_{j m}\right)\left(1+N\left(I_{j m} /(1+\delta)\right)+N\left(J_{j m}\right)\right),
\end{aligned}
$$

where $S($.$) is a decreasing returns to scale function of time spent in skill acquisition and I_{k m}$ and $J_{k m}$ denote the numbers of members of ethnic groups $I$ and $J$ in network $m$ of which individual $k$ is a member, respectively.

With two kinds of skills that increase the efficiency of time spent working, it is assumed that efficient labor is a composite of time-empowered exclusive and inclusive skills as follows

$$
H_{k}=H\left(Z_{k x} S_{k x}, Z_{k n} S_{k n}\right)
$$

where $H(.,$.$) is a well behaved production function increasing in its arguments with decreasing$ 
returns to each input. ${ }^{15}$ Given the difference of exclusive and inclusive skills, the qualitative properties of individual efficient labor are determined by the combination of skills that the individual has. I operationalize this qualitative variation of efficient labor such that efficiency units of labor that involve different (combinations of) skills are imperfect substitutes in the labor market. Thus, for example, if the skills of one individual are predominantly exclusive and the skills of another individual are predominantly inclusive, the elasticity of substitution of labor of these two individuals is finite. Formally, defining $s_{k} \equiv S_{k x} / S_{k n}$, whenever $s_{k} \neq s_{k^{\prime}}\left(s_{k}=s_{k^{\prime}}\right)$ for individuals $k$ and $k^{\prime}$, the elasticity of substitution between $H_{k}$ and $H_{k^{\prime}}$ is finite (infinite). ${ }^{16}$

To establish that there are equilibrium regimes of skill acquisition under which people of different ethnicities choose different (combinations of) skills, this section investigates the individual problem of time allocation. Individuals maximize their utility, taking their resource constraints, available technologies, network effects, wages per unit of their efficient labor, and the price level as given. Because the utility function depends only on the amount of consumption good that an individual consumes, it follows that the agents' problem boils down to

$$
\underset{L_{k m}, T_{k m}}{\operatorname{Max}}\left\{H_{k}\right\}
$$

subject to (9), (10), (11), and the resource constraints (8), $Z_{k m} \geq 0$ and $L_{k m} \geq 0$. Clearly, this maximization problem is largely determined by the elasticity of substitution between exclusive and inclusive skills. To illustrate, if these skills are good substitutes in producing $H_{k}$, the individual may choose to acquire only that skill that she can acquire more efficiently. In contrast,

\footnotetext{
${ }^{15}$ This technology of producing efficient labor $H_{k}$ can be, without any bearing on the argument of this paper, reinterpreted as the production function of the intermediate good $H_{k}$, which is an input in the production of the consumption good $C$.

${ }^{16}$ Because $s_{k}$ is determined by the organization of human capital acquisition, which is endogenous in the model, the degree of substitutability between minority and majority labor is in this sense endogenous as well. Whether we define substitutability of ethnic labor as a function of $s_{k} \equiv S_{k x} / S_{k n}$ or $s_{k} \equiv Z_{k x} S_{k x} / Z_{k n} S_{k n}$ has no bearing on the argument, as discussed in the section about the equilibrium regimes and in the Appendix.
} 
if there are strong complementarities between the two types of skills, the individual will strive to acquire both of them. The specific condition separating these two regimes under specific production technologies is derived in the Appendix.

The key question, however, is under what conditions people of different ethnicities choose different (combinations of) skills. For each individual, this choice is driven by the efficiency of skill acquisition across social networks. From (9) and (10) one can see that social distances and group sizes generate different trade-offs for members of different ethnic groups in skill acquisition. Namely, given spillover effects and social distances in skill acquisition, asymmetric sizes of ethnic groups generate asymmetric trade-offs for members of different ethnic groups and thus drive them to acquire different (combinations of) skills.

To investigate the effects of such asymmetries on equilibrium regimes of skill acquisition, I adopt the trembling hand perfect version of the Nash equilibrium. Specifically, I define stable equilibrium as the state in which no individual has incentives to deviate, that is, to change his or her allocation of time across social networks, even if, with negligible probability, individuals unintentionally play off-the-equilibrium strategies. Given this equilibrium concept, we can state the following general proposition about stable equilibrium regimes of skill acquisition:

Proposition 5: In any stable equilibrium, no agent is involved in more than one network of any given type, exclusive or inclusive.

Proof: An individual is involved in two (or more) social networks of the same type if and only if their efficiencies for this individual are the same. Given the strictly increasing spillover effects, 
in any stable equilibrium this cannot happen, however, because any perturbation of agents' involvements makes one of the networks less efficient and causes this individual to abandon it.

Similarly, if the combination of skills possessed by an individual is not directly observable in the labor market and workers are distinguished only by their ethnicity, which is a standard asymmetric information assumption, the following proposition ensues.

Proposition 6: In any stable equilibrium all members of a given ethnic group choose the same combination of skills to acquire.

Proof: If individuals take the wage for a unit of their efficient labor as given with respect to their choice of skills, individuals pick that combination of skills (and thus social networks) that they can acquire most efficiently. Consider now an equilibrium with two individuals from the same ethnic group that are involved in two different combinations of social networks. It must then be the case that the efficiencies of these two combinations of social networks for the two individuals in production of efficient labor are the same. Such equilibrium is, however, unstable. Any marginal deviation from the distribution of individuals across these two different combinations of networks causes their efficiencies to differ, given the strictly increasing spillover effects, and all individuals abandon the less efficient one.

Proposition 5 and Proposition 6 imply that at most two different types of labor are supplied in the economy, one specific for the minority and one for the majority ethnic group. ${ }^{17}$ In this sense, because these propositions do not rest on the particular specification of the

\footnotetext{
${ }^{17}$ Note that existence of at least one non-empty social network and thus the existence of a stable equilibrium is not an issue in this model, since individuals always acquire some skills (see technology 11) and thus are members of at least one social network. See also the discussion and propositions below on the stability of specific equilibria.
} 
production function (1), but on the asymmetric information assumption on which Proposition 6 hinges, this production function can be seen as a harmless simplification of a more general production technology with an arbitrary number of types of labor $H$.

To develop the argument that there are equilibria that exhibit specialization of ethnic groups, consider the case in which there are strong complementarities between exclusive and inclusive skills such that individuals necessarily acquire both types of skills. Because all agents of a given type choose the same set of networks and thus skills to acquire, as established in Proposition 6, two different equilibria can arise. In the DI equilibrium ethnic groups acquire exclusive skills in their group-specific exclusive social networks and inclusive skills in one integrated inclusive social network where both ethnic groups interact. In the DS equilibrium, in contrast, inclusive skills are acquired in two segregated inclusive social networks, one with minority and one with majority members. In this sense the DI equilibrium is integrated and the DS equilibrium segregated. ${ }^{18}$ The following proposition discusses the stability of these equilibria.

Proposition 7: The DI equilibrium is always stable. The DS equilibrium is stable if and only if the condition $I \geq 1 /(2+\delta)$ holds.

Proof: The only possibility for an individual to deviate in the DI equilibrium is to form his or her own inclusive social network. Because such network would offer zero network benefits, such deviation is never profitable and the DI equilibrium is therefore stable. Under the DS regime, $S_{i x}^{D S}=S\left(L_{i x}^{D S}\right)(1+N(I))$ and $S_{i n}^{D S}=S\left(L_{i n}^{D S}\right)(1+N(I))$. A minority individual can deviate only to majority inclusive social network, facing $S_{i n}^{D S^{\prime}}=S\left(L_{i n}^{D S^{\prime}}\right)(1+N(J /(1+\delta)))$. Thus, the DS

\footnotetext{
${ }^{18}$ Note, however, that there is a degree of segregation in the DI equilibrium as well, as the exclusive networks are by definition segregated.
} 
equilibrium is stable only if $1+N(I) \geq 1+N(J /(1+\delta))$. This condition boils down to $I \geq 1 /(2+\delta)$, given that $I+J=1$. Applying the same line of reasoning to majority individuals, we arrive at the condition $J \geq I /(1+\delta)$, which is always satisfied, however.

Do ethnic groups specialize in these equilibria? To answer this question, one needs to look at the relative efficiencies of inclusive and exclusive social networks for each ethnic group. In the DI equilibrium for the minority ethnic group these efficiencies are characterized by $S_{\text {in }}=S\left(L_{i n}\right)(1+N(I)+N(J /(1+\delta)))$ in the inclusive social network and $S_{i x}=S\left(L_{i x}\right)(1+N(I))$ in the exclusive one. The respective efficiencies for the majority ethnic group are $S_{j n}=S\left(L_{j n}\right)(1+N(I /(1+\delta))+N(J))$ and $S_{j x}=S\left(L_{j x}\right)(1+N(J))$. Therefore, the efficiency tradeoffs for minority and majority individuals are the same, if $\frac{1+N(I)+N(J /(1+\delta))}{1+N(I)}=\frac{1+N(I /(1+\delta))+N(J)}{1+N(J)}$,

which is equivalent to $N(J /(1+\delta)) /(1+N(I))=N(I /(1+\delta)) /(1+N(J))$. Clearly, this equality never holds for admissible values of $I, J$, and $\delta$ and thus minority and majority individuals are never equally efficient in exclusive and inclusive social networks in relative terms. In particular, minority individuals are relatively more (less) efficient in inclusive (exclusive) social networks than majority individuals. As a result, individuals from ethnic groups of different sizes have different incentives as concerns allocation of time between exclusive and inclusive social networks.

Whether these dissimilar incentives lead to dissimilar combinations of exclusive and inclusive skills possessed by individuals of different ethnicities is somewhat more involved a 
question. The reason is that, in order to benefit from the complementarities between exclusive and inclusive skills that are present under the DI equilibrium, individuals may want to compensate for the efficiency differentials across social networks by investing more time in acquiring or utilizing skills acquired in relatively less efficient social networks. The intuition why such compensating time investment does not lead to the same combination of skills possessed by members of different ethnic groups is straightforward. It rests on the fact that such compensating behavior is costly in terms of overall efficiency of skill acquisition and utilization, as compensating implies that relatively larger amounts of time are invested in skills that are acquired relatively less efficiently. It is these costs that prevent individuals from fully compensating for the efficiency differentials between exclusive and inclusive networks, unless $H(.,$.$) exhibits perfect complementarity between skills. Because these efficiency differentials$ vary across ethnic groups but benefits from complementarities between skills by assumption do not, as the function $H(. .$.$) is assumed to be the same for all ethnic groups, people of different$ ethnicities acquire different combination of skills. In effect, their labor is imperfectly substitutable in the labor market under the DI equilibrium. Because the efficiency differentials are a function of the relative sizes of ethnic groups, the degree of specialization and thus substitutability of labor of different ethnic groups is a function of their relative sizes. This intuitive argument about specialization under the DI equilibrium is formalized in the Appendix for specific functional forms of production technologies.

In the DS equilibrium, the efficiencies of minority and minority people in skill acquisition are characterized by $S_{\text {in }}=S\left(L_{\text {in }}\right)(1+N(I))$ in the inclusive social network and $S_{i x}=S\left(L_{i x}\right)(1+N(I))$ in the exclusive one. On the other hand, the respective efficiencies for the majority ethnic group are $S_{j n}=S\left(L_{j n}\right)(1+N(J))$ and $S_{j x}=S\left(L_{j x}\right)(1+N(J))$. Clearly, the 
efficiency trade-offs between different types of skills are the same across ethnic groups and no ethnic specialization occurs in the DS equilibrium. The following proposition summarizes these results.

Proposition 8: If exclusive and inclusive skills are not perfect complements (but exhibit sufficiently strong complementarities such that individuals acquire both types of skills), under the DI equilibrium ethnic groups of different sizes acquire different combinations of skills. No ethnic specialization occurs under the DS equilibrium, however.

If exclusive and inclusive skills are good substitutes, acquiring both types of skills is not necessary and individuals choose just one type of skills to acquire in the equilibrium. The reason is that under such condition any equilibrium in which individuals combine exclusive and inclusive skills is unstable by the same argument as discussed in the proof of Proposition 6. Five equilibria of this type are possible. First, there are three equilibria in which ethnic groups specialize in the same kind of skills, exclusive (EE) or inclusive (II, IIS). The distinction between the II and IIS equilibria is that under the II equilibrium there is only one integrated social network in the economy in which minority and majority individuals interact. On the other hand, in the IIS equilibrium minority and majority individuals form two ethnically segregated inclusive social networks. Second, there are two equilibria under which ethnic groups specialize, one ethnic group acquiring exclusive and the other one inclusive skills (EI, IE). Clearly, ethnic specialization occurs under the EI and IE equilibria, minority and majority individuals acquiring different types of skills. 
The EE, IE, and II equlibria are stable without further restrictions. Under the EE and II equilbiria no deviation to a non-empty network is possible. Under the IE equilibrium, deviation of majority people to the inclusive minority network is possible, but it is inefficient by the argument similar to the one in the proof of Proposition 7. By the same argument, finally, the EI and IIS equilibria are stable only if the condition $I \geq 1 /(2+\delta)$ is satisfied. The following proposition restates the key results on ethnic specialization under good substitutability of exclusive and inclusive skills. Figure 3 summarizes all the seven different equilibria that can arise in the economy.

Proposition 9: If exclusive and inclusive skills are good substitutes such that no individual acquires both types of skills, the IE, EE, and II equilibria are always stable. The EI and IIS equilibria are stable under the condition $I \geq 1 /(2+\delta)$. Ethnic specialization occurs in the EI and IE equilibria.

Figure 3. Equilibrium regimes of skill acquisition.

\begin{tabular}{ccccc}
\hline Equilibrium & $\begin{array}{c}\text { Skills of minority } \\
\text { people }\end{array}$ & $\begin{array}{c}\text { Skills of majority } \\
\text { people }\end{array}$ & $\begin{array}{c}\text { Stability } \\
\text { condition }\end{array}$ & $\begin{array}{c}\text { Ethnic } \\
\text { specialization }\end{array}$ \\
\hline DI & Mix of both types & Mix of both types & None & Yes \\
DS & Mix of both types & Mix of both types & $I \geq 1 /(2+\delta)$ & No \\
EE & Exclusive & Exclusive & None & No \\
EI & Exclusive & Inclusive & $I \geq 1 /(2+\delta)$ & Yes \\
IE & Inclusive & Exclusive & None & Yes \\
II & Inclusive (Integrated) & Inclusive (Integrated) & None & No \\
IIS & Inclusive (Segregated) & Inclusive (Segregated) & $I \geq 1 /(2+\delta)$ & No \\
\hline
\end{tabular}

The stability condition $I \geq 1 /(2+\delta)$ plays an important role in determining which equilibria are stable in the economy. In fact, if this condition holds, not only are all the seven 
different equilibria viable, so are they in the absence of the assumed institutional exclusivity of exclusive social networks. ${ }^{19}$ In other words, elimination of institutional exclusion in exclusive social networks does not lead to integration, whenever the size of minority or the social distance between ethnic groups is sufficiently large. Provided that this condition holds, one can generalize the argument of this paper to social contexts without institutional exclusion.

An important consequence of the dependence of the stability condition on relative group sizes is that substitutability of labor of different ethnic groups across labor markets is a function of relative group sizes. For example, in regions where ethnic minority is large enough the EI equilibrium may prevail, while this is not be possible in regions with relatively small number of minority people, since they have strong incentives to integrate and the II equilibrium prevails. It is also worthwhile to note and easy to see from the analysis above that the key result of this paper on the existence of stable equilibria under which ethnic groups specialize is robust with respect to an alternative assumption of a negative social distance, that is, "taste" for inter-ethnic social interaction.

\section{Discussion and conclusions}

This paper elucidates the nature of labor market competition between different ethnic groups as driven by their relative sizes and classifies the equilibrium regimes of human capital acquisition in the context of ethnic competition. It is shown that the counteracting substitution and efficiency effects are driving relative earnings of ethnic groups of different sizes. While the

\footnotetext{
${ }^{19}$ This result follows from the proof of Proposition 6.
} 
efficiency effect is always operative, given that there are spillover effects and inter-ethnic social distances in skill acquisition, whether the substitution effect is present or not depends on whether ethnic groups specialize in different skills. The key result is that, besides equilibria under which no specialization occurs, there are stable equilibrium regimes of skill acquisition under which ethnic groups acquire different (combinations of) skills. This result is driven by the spillover effects in skill acquisition that, given the positive social distance between ethnic groups, expose different ethnic groups to different efficiency tradeoffs in acquisition of skills acquired in exclusive social networks, such as the family, and inclusive social networks, such as the school.

Which of the multiple equilibria possibly arising in the economy prevails depends especially on the degree of complementarity between exclusive and inclusive skills that determines whether individuals acquire both or just one type of skills. Relative group sizes and social distances between ethnic groups are the key determinants of stability of these equilibria. The multiplicity of equilibria is in fact informative in the light of the mixed results of the studies on the substitutability of ethnic labor. In particular, it implies that the nature of ethnic competition may vary across labor markets such that in some labor markets labor of different ethnic groups is perfectly substitutable while imperfect substitutability prevails in others.

Specifically, this study shows that the degree of specialization of ethnic groups and thus the substitutability of labor of different ethnic groups is a function of their relative sizes. This result stems from the size-dependent efficiency trade-offs in skill acquisition in the DI equilibrium that imply that time and skill allocations depend on relative sizes of ethnic groups. Another reason why the relative size of ethnic groups matters for ethnic specialization is the dependence of the stability of some equilibria on the size-dependent stability condition that may decide between equilibria with perfectly and imperfectly substitutable labor of different ethnic 
groups. For example, if the size of the minority community (and thus the spillover benefits it generates) decreases, minority individuals previously specialized in skills acquired in exclusive social networks such as their kinship network may find it efficient to integrate into inclusive social networks such as the school.

Hence, specialization is viable even for a relatively small minority, whenever (i) a sufficiently large social distance sustains the EI equilibrium, (ii) ethnic majority prevents ethnic minority from their exclusive social networks sustaining the IE equilibrium, or (iii) strong complementarities between exclusive and inclusive skills result in the DI equilibrium. Under such circumstances, the substitution effect may, depending on the parameters of the model, outweigh the efficiency effect and drive the earnings of ethnic minority above those of ethnic majority. This paper thus also offers an explanation of why and under what circumstances ethnic minorities may attain higher earnings than majorities.

From the policy perspective, this paper shows that one-off policy measures that induce people to switch between exclusive and inclusive social networks may be effective in improving the overall efficiency of the economy. In particular, a policy maker may wish to achieve integration in order to increase the size of social networks and thus the efficiency benefits from spillover effects. However, any such policy must be carefully considered for the price effects of integration that may arise in those cases when the policy leads to (de-)specialization of ethnic groups and thus affects the substitution effect. Furthermore, the effects of such policies on aggregate production also depend on the strength of complementarities between human capitals of different ethnic groups. From a different perspective, integration does not necessarily lead to elimination of ethnic specialization, as evidenced by the DI equilibrium. 
Appendix (Derivation of equilibrium properties using specific functional forms)

To establish the results discussed in Proposition 8 in a more specific setup, I introduce specific functional forms for the aggregate production technology (1) and technologies (9), (10), and (11) to analytically solve the model. Let the consumption good be produced in a perfectly competitive industry according to the constant elasticity of substitution (CES) aggregate production function

$$
C=\left(\left(\int_{0}^{I} H_{i} d i\right)^{(\rho-1) / \rho}+\left(\int_{0}^{J} H_{j} d j\right)^{(\rho-1) / \rho}\right)^{\rho /(\rho-1)}
$$

with the elasticity of substitution $\rho>1$. According to this specification, labor of any given type has decreasing marginal returns, production exhibits constant returns to scale, and no type of labor is essential in production.

Furthermore, I assume the constant elasticity of substitution technology of producing $H_{k}$ efficiency units of labor

$$
H_{k}=\left[\left(S_{k x} Z_{k x}\right)^{(\varepsilon-1) / \varepsilon}+\left(S_{k n} Z_{k n}\right)^{(\varepsilon-1) / \varepsilon}\right]^{\varepsilon /(\varepsilon-1)},
$$

where the finite and positive parameter $\varepsilon$ denotes the elasticity of substitution between timeempowered exclusive and inclusive skills in production of individual efficient labor and reflects their imperfect substitutability. Skills are acquired in social networks according to a decreasingreturns-to-scale technology

$$
\begin{aligned}
& S_{i m}=L_{i m}^{\phi}\left(1+N\left(I_{i m}\right)+N\left(J_{i m} /(1+\delta)\right)\right) \\
& S_{j m}=L_{j m}^{\phi}\left(1+N\left(I_{j m} /(1+\delta)\right)+N\left(J_{j m}\right)\right)
\end{aligned}
$$

where $\phi \in(0,1]$ is the measure of decreasing returns to time spent in skill acquisition. 
Solving the individual problem (12) with the technologies (A1), (A2), (A3), (A4), and the resource constraint (8), one can show that in the equilibrium individuals divide their time between acquisition and utilization of skills according to the rule

$$
L_{k m}=\phi Z_{k m} .
$$

Thus, agent $k$ allocates $\phi$ units of her time to acquisition of skill $m$ for each unit of time spent utilizing this skill in production. It also turns out that the condition $\varepsilon<(\phi+1) / \phi$ separates two classes of regimes. In particular, if exclusive and inclusive skills are good substitutes such that $\varepsilon \geq(\phi+1) / \phi$, individuals acquire only one type of skills. On the other hand, if $\varepsilon<(\phi+1) / \phi$, individuals choose to acquire both exclusive and inclusive skills, as there are strong complementarities between these skills. The optimal time allocation in this case is governed by the arbitrage condition

$$
Z_{k} \equiv \frac{Z_{k x}}{Z_{k n}}=\left(\frac{1+N\left(I_{k x}\right)+N\left(J_{k x} /(1+\delta)\right)}{1+N\left(I_{k n}\right)+N\left(J_{k n} /(1+\delta)\right)}\right)^{\frac{\varepsilon-1}{1+\phi-\varepsilon \phi}}=\frac{L_{k x}}{L_{k n}} \equiv l_{k} .
$$

Denoting $l_{k} \equiv \lambda_{k} \equiv z_{k}$, conditions (A5) and (A6) give rise to equilibrium time allocations $Z_{k x}=\lambda_{k} /\left(1+\lambda_{k}\right)(1+\phi)$ and $Z_{k n}=1 /\left(1+\lambda_{k}\right)(1+\phi)$ for the time spent working and $L_{k x}=\phi \lambda_{k} /\left(1+\lambda_{k}\right)(1+\phi)$ and $L_{k n}=\phi /\left(1+\lambda_{k}\right)(1+\phi)$ for the time spent in skill acquisition. The relative investment of individuals in acquisition of exclusive and inclusive skills is fully determined by the spillover effects $N_{k m} \cdot{ }^{20}$

Specifying the functional forms of these spillover effects to be

$$
\begin{aligned}
& N_{i m}\left(I_{i m}, J_{i m}, \delta\right)=I_{i m}^{\gamma}+\left(J_{i m} /(1+\delta)\right)^{\gamma} \\
& N_{j m}\left(I_{j m}, J_{j m}, \delta\right)=\left(I_{j m} /(1+\delta)\right)^{\gamma}+J_{j m}^{\gamma},
\end{aligned}
$$

\footnotetext{
${ }^{20}$ In particular, it does not depend on wages. The reason is that individuals take wages as given, time has no other value but in skill acquisition, and skill acquisition does not involve any pecuniary exchange.
} 
where the parameter $\gamma>0$ captures the returns to network size. The actual spillover effects depend on the equilibrium organization of skill acquisition. In the DI equilibrium, the spillover effects $\quad$ are $\quad N_{i x}^{D I}(., . .)=.I^{\gamma}, \quad N_{i n}^{D I}(., . .)=.I^{\gamma}+(J /(1+\delta))^{\gamma}, \quad N_{j x}^{D I}(., . .)=.J^{\gamma} \quad$ and $N_{j n}^{D I}(., .,)=.(I /(1+\delta))^{\gamma}+J^{\gamma}$. This yields the minority and majority arbitrage conditions $\lambda_{i}^{D I}=\left(\frac{1+I^{\gamma}}{1+I^{\gamma}+(J /(1+\delta))^{\gamma}}\right)^{\frac{\varepsilon-1}{1+\phi-\varepsilon \phi}}$ and $\lambda_{j}^{D I}=\left(\frac{1+J^{\gamma}}{1+(I /(1+\delta))^{\gamma}+J^{\gamma}}\right)^{\frac{\varepsilon-1}{1+\phi-\varepsilon \phi}}$, respectively.

Recalling that $I<J$ and $\delta>0$ it is straightforward to observe that $\frac{1+I^{\gamma}}{1+I^{\gamma}+(J /(1+\delta))^{\gamma}}<\frac{1+J^{\gamma}}{1+(I /(1+\delta))^{\gamma}+J^{\gamma}}<1$. Given that under the DI equilibrium $\varepsilon<(\phi+1) / \phi$, from the arbitrage conditions it follows that each individual spends more time in exclusive networks than in inclusive ones whenever $\varepsilon<1$. Furthermore, in such case minority individuals spend relatively more time in exclusive social networks than majority individuals. These results arise as the consequence of skill complementarity that forces individuals to compensate for their lower efficiency in exclusive networks by the longer times spent in these networks. Similarly, if $\varepsilon>1$, in the DI equilibrium each individual spends more time in inclusive networks than in exclusive ones. Finally, if the technology of combining skills is Cobb-Douglas and $\varepsilon=1$, individuals spend equal shares of their time in exclusive and inclusive networks.

To show ethnic specialization under DI equilibrium, using the skill acquisition technologies and the arbitrage conditions, we see that

$$
s_{i}^{D I}=\left(l_{i}^{D I}\right)^{\phi}\left(1+I^{\gamma}\right) /\left(1+I^{\gamma}+(J /(1+\delta))^{\gamma}\right)=\left(\frac{1+I^{\gamma}}{1+I^{\gamma}+(J /(1+\delta))^{\gamma}}\right)^{\frac{1}{1+\phi-\varepsilon \phi}},
$$

whereas 
$s_{j}^{D I}=\left(l_{j}^{D I}\right)^{\phi}\left(1+J^{\gamma}\right) /\left(1+(I /(1+\delta))^{\gamma}+J^{\gamma}\right)=\left(\frac{1+J^{\gamma}}{1+(I /(1+\delta))^{\gamma}+J^{\gamma}}\right)^{\frac{1}{1+\phi-\varepsilon \phi}}$.

By the same argument as above, it follows that $s_{i}^{D I} / s_{j}^{D I}<1$, since $\varepsilon<(1+\phi) / \phi$ under DI equilibrium. In particular, even though minority agents under some circumstances spend more time in their exclusive networks in the DI equilibrium, they unambiguously acquire relatively less exclusive skills than majority individuals. It is easy to see that $z_{i}^{D I} s_{i}^{D I}=\left(\frac{1+I^{\gamma}}{1+I^{\gamma}+(J /(1+\delta))^{\gamma}}\right)^{\frac{\varepsilon}{1+\phi-\varepsilon \phi}}$ and $z_{j}^{D I} s_{j}^{D I}=\left(\frac{1+J^{\gamma}}{1+(I /(1+\delta))^{\gamma}+J^{\gamma}}\right)^{\frac{\varepsilon}{1+\phi-\varepsilon \phi}}$.

Therefore, whether we define ethnic specialization to prevail if $s_{i}^{D I} / s_{j}^{D I} \neq 1$ or $z_{i} s_{i}^{D I} / z_{j} s_{j}^{D I} \neq 1$ has no bearing on the result that the DI equilibrium exhibits specialization of ethnic groups. 


\section{References}

Aigner, Dennis, and Glen Cain. 1977. "Statistical Theories of Discrimination in Labor Markets." Industrial and Labor Relations Review, 30(2): 175-87.

Akerlof, George A. 1997. "Social Distance and Social Decisions.” Econometrica, 65(5): 100527.

Allen, Beth. 1982. “Some Stochastic Processes of Interdependent Demand and Technological Diffusion of an Innovation Exhibiting Externalities among Adopters." International Economic Review, 23(3): 595-607.

Altonji, Joseph G., and Rebecca M. Blank, 1998. "Race and Gender in the Labor Market.” In Handbook of Labor Economics, edited by Orley Ashenfelter and David Card, Vol. 3c, 3143259. Amsterdam: Elsevier.

Arrow, Kenneth J. 1972a. "Models of Job Discrimination." In Racial Discrimination in Economic Life, edited by Anthony H. Pascal, 83-102. Lexington, Mass: D.C. Heath.

Arrow, Kenneth J. 1972b. "Some Mathematical Models of Race Discrimination in the Labor Market,” In Racial Discrimination in Economic Life, edited by Anthony H. Pascal, 187-204. Lexington, Mass: D.C. Heath.

Arrow, Kenneth J. 1973. "The Theory of Discrimination." In Discrimination in the Labor Markets, edited by Orley Ashenfelter and Albert Rees, 3-33. Princeton, N.J.: Princeton University Press.

Bala, Vanketash, and Sanjeev Goyal. 1998. "Learning from Neighbors.” Review of Economic Studies, 65: 595-621.

Becker, Gary. 1956. The Economics of Discrimination, Chicago: University of Chicago Press.

Blalock, Hubert M. Jr. 1956. "Economic Discrimination and Negro Increase." American Sociological Review, 21(5): 584-8.

Blalock, Hubert M. Jr. 1957. "Per Cent Non-White and Discrimination in the South.” American Sociological Review, 22(6): 677-82.

Borjas, George J. 1983. "The Substitutability of Black, Hispanic, and White Labor.” Economic Inquiry, 21(1): 93-106.

Borjas, George J. 1987. "Immigrants, Minorities, and Labor Market Competition.” Industrial and Labor Relations Review, 40(3): 382-92.

Borjas, George J. 2003. "The Labor Demand Curve Is Downward Sloping: Reexamining the Impact of Immigration on the Labor Market.” The Quarterly Journal of Economics, 118(4): 1335-74.

Brown, David L., and Glenn V. Fuguitt. 1972. "Percent Nonwhite and Racial Disparity in Nonmetropolitan Cities of the South.” Social Science Quarterly, 53(December): 573-82.

Buhai, Sebastian and Marco van der Leij. 2006. "A Social Network Analysis of Occupational Segregation.” Tinbergen Institute Discussion Paper TI 2006-016/1 .

Coate, Stephen, and Glenn Loury. 1993. "Will Affirmative Action Policies Eliminate Negative Stereotypes.” American Economic Review, 83(5): 1220-42.

Coleman, J. S., E. Campbell, C. Hubson, J. McPartland, A. Mood, F. Weinfeld, and R. York. 1966. Equality of Educational Opportunity. Washington D.C.: U.S. Government Printing Office.

Conley, Timothy, and Christopher Udry. 2005. "Learning about a New Technology: Pineapple in Ghana.” Federal Reserve Bank of San Francisco Proceedings. 
Ellison, Glenn, and Drew Fudenberg. 1993. "Rules of Thumb for Social Learning.” Journal of Political Economy, 101(4): 612-43.

Ellison, Glenn, and Drew Fudenberg. 1995. "Word-of-Mouth Communication and Social Learning.” Quarterly Journal of Economics, 110(1): 83-97.

Feick, Lawrence F., and Linda L. Price. 1987. "The Market Maven: A Diffuser of Marketplace Information.” Journal of Marketing, 51(1): 83-97.

Foster, Andrew D., and Mark R. Rosenzweig. 1995. "Learning by Doing and Learning from Others: Human Capital and Technical change in Agriculture.” Journal of Political Economy, 103(6): 1176-209.

Frisbie, Parker W., and Lisa Neidert. 1977. "Inequality and the Relative Size of Minority Populations: A Comparative Analysis.” The American Journal of Sociology, 82(5): 1007-30.

Gladwell, Malcolm. 2000. The tipping point: how little things can make a big difference. Boston: Little, Brown.

Glaeser, Edward L., David Laibson, and Bruce Sacerdote. 2002. "An Economic Approach to Social Capital.” The Economic Journal, 112(483): 437-58.

Grant, James H., and Daniel Hamermesh. 1981. "Labor Market Competition among Youths, White Women, and Others.” The Review of Economics and Statistics, 63(3): 354-60.

Grossman, Jean Baldwin. 1982. "The Substitutability of Natives and Immigrants in Production.” The Review of Economics and Statistics, 64(4): 596-603.

Heckman, James J. 2000. "Policies to Foster Human Capital.” Research in Economics, 54(1): 356.

Heer, David M. 1959. "The Sentiment of White Supremacy and Ecological Study." The American Journal of Sociology, 64(6): 592-8.

Hicks, John. 1970. "Elasticity of Substitution Again: Substitutes and Complements." Oxford Economic Papers, 22(3): 289-96.

Hirschman, Charles, and Morrison G. Wong. 1984. "Socioeconomic Gains of Asian Americans, Blacks, and Hispanics: 1960-1976.” The American Journal of Sociology, 90(3): 584-607.

Hofstede, Geert H. 1980. Culture's Consequences: International Differences in Work-related Values. Beverly Hills, California: Sage Publications.

Kahanec, Martin. 2006a. "The Substitutability of Labor of Selected Ethnic Groups in the US Labor Market.” IZA Discussion Paper 1945.

Kahanec, Martin. 2006b. "Ethnic Specialization and Earnings Inequality: Why Being a Minority Hurts but Being a Big Minority Hurts More” IZA Discussion Paper 2050.

Lazear, Edward P. 1999. "Culture and Change.” The Journal of Political Economy, 107(6): 95126.

Lucas, Robert E. Jr. 1988. “On the Mechanics of Economic Development.” Journal of Monetary Economics, 22(1): 3-42.

Lundberg, Shelly, and Richard Startz. 1998. “On the Persistence of Racial Inequality.” Journal of Labor Economics, 16(2): 292-323.

Munshi, Kaivan. 2004. "Social Learning in a Heterogeneous Population: Technology Diffusion in the Indian Green Revolution.” Journal of Development Economics, 73(1): 185-215.

Phelps, Edmund S. 1972. "The Statistical Theory of Racism and Sexism." American Economic Review, 62(4): 659-61.

Poole, Willard C. Jr. 1927. "Distance in Sociology.” The American Journal of Sociology, 33(1): 99-104. 
Richman, Barak D. 2006. "How Community Institutions Create Economic Advantage: Jewish Diamond Merchants in New York.” Law and Social Inquiry, 31(2): 383-420.

Tienda, Marta, and Ding-Tzann Lii. 1987. "Minority Concentration and Earnings Inequality: Blacks, Hispanics, and Asians Compared.” The American Journal of Sociology, 93(1): 14165.

Valente, Thomas W. 1995. Network Models of the Diffusion of Innovations. Cresskill, NJ: Hampton Press, Inc.

Welch, Finis. 1967. "Labor Market Discrimination: An Interpretation of Income Differences in the Rural South.” Journal of Political Economy, 75(3): 225-40. 